\begin{tabular}{|} 
Ambiente \& Água - An Interdisciplinary Journal of Applied Science \\
ISSN 1980-993X - doi:10.4136/1980-993X \\
www.ambi-agua.net \\
E-mail: ambi.agua@gmail.com
\end{tabular}

\title{
Peroxidase de gramínea de Cerrado como alternativa no tratamento de efluentes agroindustriais
}

\author{
doi:10.4136/ambi-agua.1735
}

Received: 20 Aug. 2015; Accepted: 26 Sep. 2015

\author{
Raquel Pinheiro Reis Souza Ramalho'; Paulo Sérgio Scalize"; \\ Samantha Salomão Caramori ${ }^{2 *}$ \\ ${ }^{1}$ Universidade Federal de Goiás (UFG), Goiânia, GO, Brasil \\ Escola de Engenharia Civil e Ambiental \\ ${ }^{2}$ Universidade Estadual de Goiás (UEG), Anápolis, GO, Brasil \\ Câmpus de Ciências Exatas e Tecnológicas (CCET) \\ *Autor correspondente: e-mail: sscaramori@gmail.com, \\ rprs.ramalho@hotmail.com, pscalize.ufg@gmail.com
}

\section{RESUMO}

A despoluição de águas residuais é ainda um desafio para a sociedade e comunidade acadêmica. Diante dos diversos materiais disponíveis para estudo destacam-se as enzimas, em função de sua especificidade para a despoluição e biodegradabilidade para descarte. Novas fontes de enzimas podem representar alternativas eficientes e de custo reduzido em relação às técnicas corriqueiramente utilizadas. Neste trabalho o perfil de peroxidase dos frutos de Echinolaena inflexa foi estudado para aplicação no tratamento de águas residuais. $\mathrm{O}$ teor de proteína encontrado foi 5,33 $\mathrm{mg} \mathrm{g}^{-1}$. As condições ótimas de reação foram: $50^{\circ} \mathrm{C}$, pH 7,5 a 0,1 mol L ${ }^{-1}$ de tampão fosfato e $15 \mathrm{~min}$. A enzima foi inativada somente após aquecimento a $94^{\circ} \mathrm{C}$ e teve sua atividade inibida quando incubada com ácido ascórbico a $10 \mathrm{mmol} \mathrm{L}^{-1}$, um inibidor clássico para peroxidases. Nos testes com fenóis e efluentes agroindustriais, a enzima foi capaz de degradar $87,5 \%$ do catecol, $67,8 \%$ do pirogalol e $39,1 \%$ do resorcinol e ainda apresentou $29,1 \%$ de capacidade de degradação de compostos fenólicos presentes no efluente bruto. Os resultados mostraram que a peroxidase de Echinolaena inflexa, uma nova fonte de enzimas, possui potencial para ser explorada como alternativa ao tratamento de águas residuais.

Palavras-chave: Echinolaena inflexa, fenóis, peroxidase, poaceae.

\section{Peroxidase of Brazilian Cerrado grass as an alternative for agro.industrial waste treatment}

\begin{abstract}
Decontamination of wastewater continues to be a challenge for society and the scientific community. Despite the availability of various materials for study, enzymes stand out due to their specificity for decomposition and biodegradability for disposal. New sources of enzymes may represent efficient and low-cost alternatives compared to routinely used techniques. In this survey, the peroxidase profile from Echinolaena inflexa fruits was studied for possible
\end{abstract}


applications in the treatment of wastewater. The protein content was found to be $5.33 \mathrm{mg} \mathrm{g}^{-1}$. The optimum reaction conditions were: $50^{\circ} \mathrm{C}, \mathrm{pH} 7.5$ at $0.1 \mathrm{~mol} \mathrm{~L}^{-1}$ of phosphate buffer for $15 \mathrm{~min}$. The enzyme was inactivated after $5 \mathrm{~min}$ at $94^{\circ} \mathrm{C}$ and was inhibited when incubated with ascorbic acid at $10 \mathrm{mmol} \mathrm{L}^{-1}$. In tests using phenols and agro industrial waste, the peroxidase was able to oxidase $87.5 \%$ of catechol, $67.8 \%$ of pyrogallol, $39.1 \%$ of resorcinol and still presented $29.1 \%$ of the degradation capacity of raw wastewater phenolic compounds. The results showed that the Echinolaena inflexa peroxidase, a new source of enzymes, is a potential alternative to wastewater treatment.

Keywords: Echinolaena inflexa, peroxidase, phenols, Poaceae.

\section{INTRODUÇÃO}

Um dos grandes impactos ambientais no mundo é a destinação inadequada de efluentes no meio ambiente. Efluentes não tratados promovem uma grave poluição hídrica, além de transportarem diferentes tipos de vírus, bactérias e protozoários nocivos à saúde pública (Mannarino et al., 2013). A partir dessa necessidade de tratamento, surgem diferentes processos, sendo alguns mais eficientes, baratos e ambientalmente corretos para a degradação de diversos compostos orgânicos.

As enzimas fazem parte desses processos e são reconhecidas como catalisadores biológicos, apresentando características importantes, tais como a atuação em condições amenas de reação, a alta especificidade, a biodegrabilidade e a alta eficiência catalítica. Dentre as classes de enzimas, as oxidorredutases possuem um dos principais papeis na degradação de compostos orgânicos, uma vez que catalisam reações de transferência de elétrons e as peroxidases, subclasse de oxidorredutases, oxidam os diferentes compostos na presença de peróxido de hidrogênio ou peróxidos orgânicos, gerando radicais livres (Chance e Maehly, 1955).

Dentro do contexto de tratamento de efluentes, cabe às peroxidases um papel de destaque, em função da sua capacidade em degradar substâncias tóxicas e persistentes. Segundo Neves e Silva (2007), essas enzimas são amplamente encontradas em vegetais, e estão ligadas à função fisiológica/bioquímica da planta. A maioria dos relatórios sobre a desintoxicação de águas residuais contaminadas com fenóis, cresóis e fenóis clorados usou peroxidase das raízes de Rábano Silvestre (Armoracia rusticana), na forma purificada com a denominação de HRP (Horseradish Peroxidase). Recentemente, peroxidases de outras fontes, como melão-de-são-caetano (Momordica charantia L.), nabo (Brassica rapa L.) e copaíba (Copaifera langsdorffii Desf.) foram sugeridas como alternativas a HRP (Akhtar e Husain, 2006; Maciel et al., 2006). Características deste processo, tais como o efeito do pH, concentração do substrato, tempo de reação e os efeitos de alguns aditivos tem sido estudados para otimizar as condições de reação (Hamid e Khalil-Ur-Rehman, 2009).

Dentre a diversidade de espécies existentes e com potencial para extração enzimática, temos a vegetação do Cerrado, o segundo maior bioma brasileiro, com mais de 6000 espécies distribuídas em sua região principal de ocorrência, o Planalto Central brasileiro (Ratter et al., 1997).

Estudos florísticos e fitossociológicos que analisaram o componente herbáceo do Cerrado encontraram um predomínio da família Poaceae, principalmente dos gêneros Andropogon, Axonopus, Paspalum, Echinolaena e Trachypogon. A espécie Echinolaena inflexa (Poir.) Chase, é uma gramínea nativa, amplamente distribuída e com alta produção de biomassa (Munhoz e Felfili, 2007). Embora essas espécies venham sendo utilizadas para vários fins, tais como medicinal e alimentar, ainda há necessidade de maiores estudos viabilizando outras formas de aproveitamento de seus espécimes. 
No presente trabalho foram produzidos extratos de Echinolaena inflexa a fim de encontrar atividade de peroxidase termoestável, uma vez que essas plantas ficam expostas a longos períodos sob o sol. Avaliou-se a aplicação das enzimas obtidas nesses extratos, na degradação de diferentes compostos fenólicos, como proposta no tratamento de efluentes agroindustriais.

\section{MATERIAL E MÉTODOS}

\subsection{Extração e avaliação da atividade de peroxidase de $E$. inflexa}

A gramínea E. inflexa foi coletada na trilha do Tatu, no Campus Dr. Henrique Santillo da Universidade Estadual de Goiás, localizado no município de Anápolis, estado de Goiás-Brasil, $16^{\circ} 22^{\prime} 53,6^{\prime \prime}$ de latitude Sul e 4856'41,9”'de longitude Oeste.

A parte selecionada para estudo foi composta dos frutos de Echinolaena inflexa, que foram coletados e triturados em moinho tipo martelo (TE-330 Tecnal), resultando em uma farinha que foi utilizada nos experimentos. A farinha foi embalada e estocada em recipientes de polipropileno a $-10^{\circ} \mathrm{C}$.

A obtenção dos extratos brutos foi avaliada de acordo com um planejamento fatorial $2^{3}$. Foram avaliados os parâmetros tempo de extração (30-90 min) e o pH de extração. Os extratos foram obtidos utilizando diferentes tampões: pH 6,0 - 8,0 fosfato de sódio 0,1 mol L ${ }^{-1}$ e pH 9,0 borato de sódio $0,1 \mathrm{~mol} \mathrm{~L}^{-1}$. Para o preparo dos extratos, $10 \mathrm{~mL}$ de tampão foram misturados a 0,5 g de farinha (Echinolaena inflexa), agitados (tempo de extração) e depois centrifugados (5000 rpm) por 15 min. Aquele tratamento, determinado pela combinação dos dois parâmetros, que demonstrou melhor desempenho na extração das enzimas estudadas foi selecionado para o preparo dos extratos utilizados ao longo deste trabalho.

Foram avaliados os parâmetros cinéticos $\mathrm{pH}$ e temperatura de reação, obedecendo a um planejamento fatorial $2^{4}$. O pH ótimo de reação foi avaliado pela incubação das amostras de extrato com soluções com pH diferentes. Em pH 5,0 foi utilizado o tampão acetato de sódio $0,1 \mathrm{~mol} \mathrm{~L}^{-1}$; entre o pH 6,0 e 8,0 o tampão fosfato de sódio $0,1 \mathrm{~mol} \mathrm{~L}^{-1}$. A temperatura ótima foi determinada pela variação da temperatura do ensaio de atividade enzimática, entre 30 e $60^{\circ} \mathrm{C}$, em intervalos de $10^{\circ} \mathrm{C}$, em banho-maria.

O tempo de reação com os substratos foi testado pelo acompanhamento da formação de produto por unidade de tempo, após a determinação dos parâmetros ótimos de extração e reação. A atividade de peroxidase das amostras foi medida mediante a variação dos seguintes intervalos de tempo: uma medida por minuto, entre 1 a $5 \mathrm{~min}$; uma medida a cada $5 \mathrm{~min}$, entre 5 e 20 min; uma medida a cada 10 min, entre 20 e 30 min e medidas a cada 30 min, entre 30 e $60 \mathrm{~min}$.

A análise do perfil enzimático foi realizada considerando-se a atividade de peroxidase. Esse ensaios foram efetuados de acordo com a metodologia de Halpin et al. (1989) utilizando pirogalol e peróxido de hidrogênio como substratos. Os resultados foram avaliados por medida espectrofotométrica a $420 \mathrm{~nm}$ e a leitura da atividade foi feita após 1 min de reação. A atividade enzimática foi medida em unidades de enzima $\mathrm{g}^{-1}$ de farinha (atividade inespecífica). Uma unidade de enzima foi considerada como aquela capaz de produzir um aumento equivalente a 0,100 na absorbância.

A concentração de proteínas totais (solúveis) foi determinada pela metodologia descrita por Bradford (1976), por meio de leitura espectrofotométrica, a $595 \mathrm{~nm}$. A quantidade de proteína, expressa em $\mathrm{mg} \mathrm{g}^{-1}$ de farinha, foi determinada por uma curva padrão de reagente Bradford com solução de albumina sérica bovina (Sigma-Aldrich, EUA), nas concentrações de 0,05 a $0,5 \mu \mathrm{g} \mu \mathrm{L}^{-1}$. A partir dos dados de concentração proteica calculou-se a atividade de específica de peroxidase, que foi expressa em unidade de enzima por mg de proteína. 
A estabilidade da peroxidase foi verificada pela incubação do extrato sob temperatura de ebulição $\left(94^{\circ} \mathrm{C}\right)$ durante 5, 10, 15, 30, 60 e 120 min, seguida de resfriamento em banho de gelo por 5 min, e leitura de atividade residual.

O efeito de substâncias inibidoras foi testado pela incubação a $37^{\circ} \mathrm{C}$ por $90 \mathrm{~min}$. de ácido cítrico e ácido ascórbico nas concentrações de $10 \mathrm{mmol} \mathrm{L}^{-1}$ e $50 \mathrm{mmol} \mathrm{L}^{-1}$, com extratos de $E$. inflexa.

\subsection{Uso potencial de peroxidase de $E$. inflexa para degradação de compostos fenólicos}

Foram realizados testes com compostos fenólicos e efluentes agroindustriais após estabelecimento dos parâmetros ótimos, baseados na metodologia de Akhtar e Husain (2006). As amostras de efluentes foram coletadas na Estação de Tratamento de Efluentes (ETE) do Distrito Agroindustrial de Anápolis (DAIA), localizada entre os paralelos $16^{\circ} 20^{\prime}$ e $16^{\circ} 30^{\prime} \mathrm{S}$ e os meridianos 48 $50^{\prime}$ e $49^{\circ} 00^{\prime} \mathrm{W}$. Na área do DAIA tem-se o Córrego Abraão, que está localizado em uma área de aproximadamente 29 ha. A carga orgânica atual contida no esgoto bruto, segundo o Departamento de Meio Ambiente do DAIA em 2015, após coleta de 24 h é de $3.750 \mathrm{~kg}$ DBO.dia ${ }^{-1}$. Em triplicata, $0,1 \mathrm{~mL}$ do extrato bruto foi incubado com 0,75 mL da solução de três compostos fenólicos: pirogalol, catecol e resorcinol $\left(1,0 \mathrm{mmol} \mathrm{L}^{-1}\right)$, bem como, com cada amostra de efluente: bruto, efluente tratado da Estação de Tratamento de Efluentes (ETE) do DAIA e a montante e a jusante do lançamento da ETE no Córrego Abraão, com adição de $0,15 \mathrm{~mL}\left(0,75 \mathrm{mmol} \mathrm{L}^{-1}\right)$ de peróxido de hidrogênio. Em seguida, a mistura foi agitada (vórtex) e incubada a $37^{\circ} \mathrm{C}$ por $90 \mathrm{~min}$. Posteriormente, foram retiradas alíquotas de 0,2 mL para a medida da concentração residual de fenóis pela metodologia de Lowry et al. (1951). Os tubos controle foram utilizados com as soluções de fenóis e peróxido de hidrogênio em substituição ao extrato enzimático e os tubos brancos foram constituídos de água destilada em substituição ao volume de extrato. $\mathrm{O}$ experimento foi realizado em triplicata, e a partir das médias e desvio padrão foram realizados gráficos de superfície usando o programa SigmaPlot versão 12.0.

\section{RESULTADOS E DISCUSSÃO}

Nos experimentos realizados com Echinolaena inflexa foi encontrada uma concentração de proteína solúvel de $5,33 \mathrm{mg} \mathrm{g}^{-1}$. A determinação da atividade enzimática dos extratos brutos de Echinolaena inflexa para peroxidase, em diferentes valores de $\mathrm{pH}$ e tempo de extração, permitiu encontrar as condições ótimas de extração destas enzimas. A relação entre $\mathrm{pH}$, tempo de extração e $\mathrm{U} \mathrm{g}^{-1}$ é demonstrada na Figura 1.

De acordo com os resultados obtidos, a região entre o $\mathrm{pH} 7,5$ e 8,5 foi a que apresentou atividade enzimática superior às demais, e por esta razão o $\mathrm{pH}$ 8,0 foi considerado como o ótimo para a extração das peroxidases da gramínea. A peroxidase de Echinolaena inflexa foi melhor extraída quando o $\mathrm{pH}$ de extração foi combinado à variação do tempo de extração. $\mathrm{Na}$ Figura 1 é também possível observar que a partir de 90 min obteve-se a maior quantidade de enzima ativa extraída.

As condições ótimas de reação mostraram que o efeito da temperatura numa reação enzimática pode ser observado inicialmente pelo aumento progressivo na atividade, devido ao aumento da velocidade de formação do produto e consequentemente consumo do substrato (Figura 2). Todavia, verifica-se que acima de $55^{\circ} \mathrm{C}$ começa a ocorrer perda gradativa da atividade, possivelmente devido à desnaturação proteica pelo calor, como resultado da perda da conformação nativa (Figura 2) 


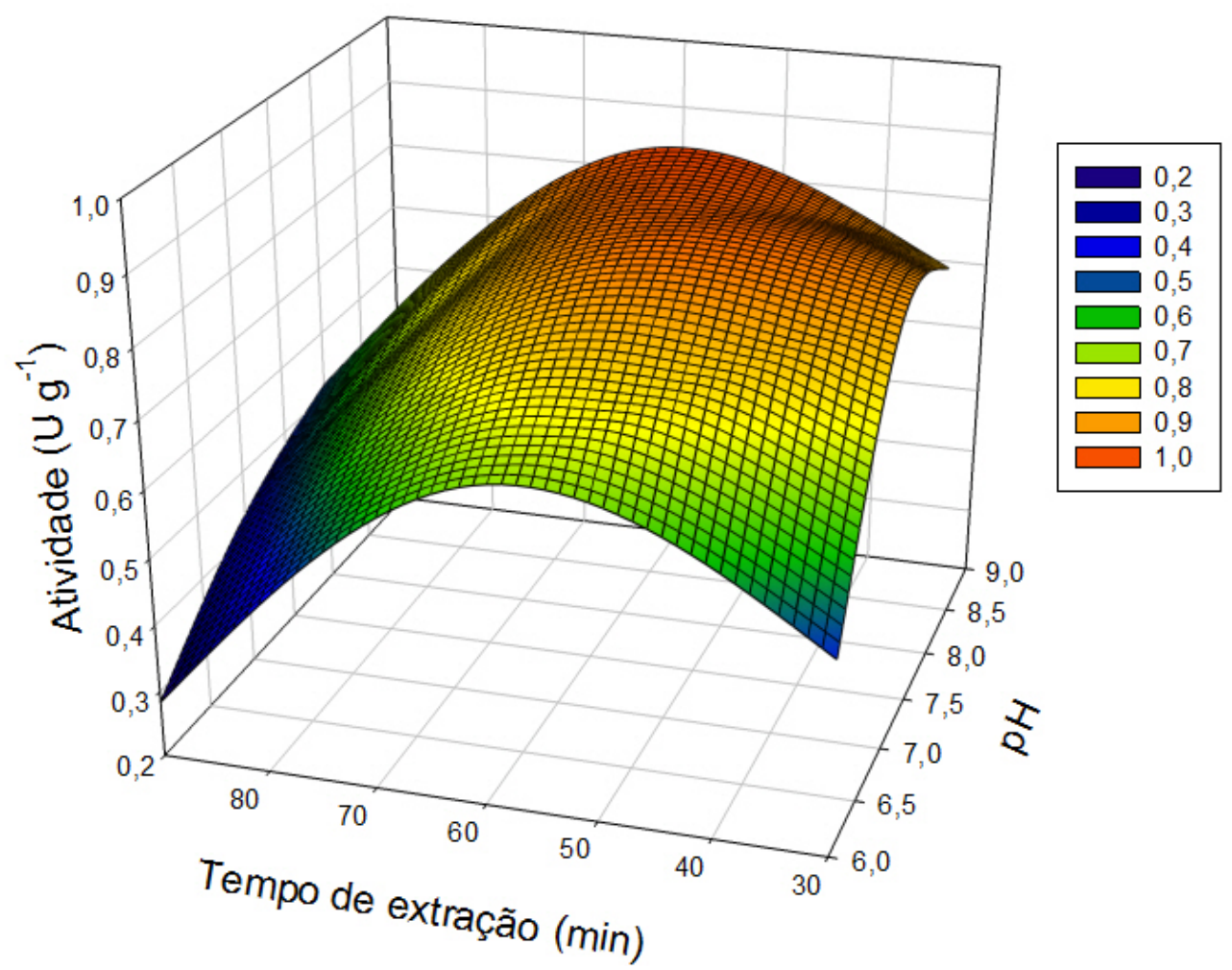

Figura 1. Efeito combinado entre o $\mathrm{pH}$ e o tempo de extração sobre a atividade de peroxidase de Echinolaena inflexa $\left(\mathrm{Ug}^{-1}\right)$.

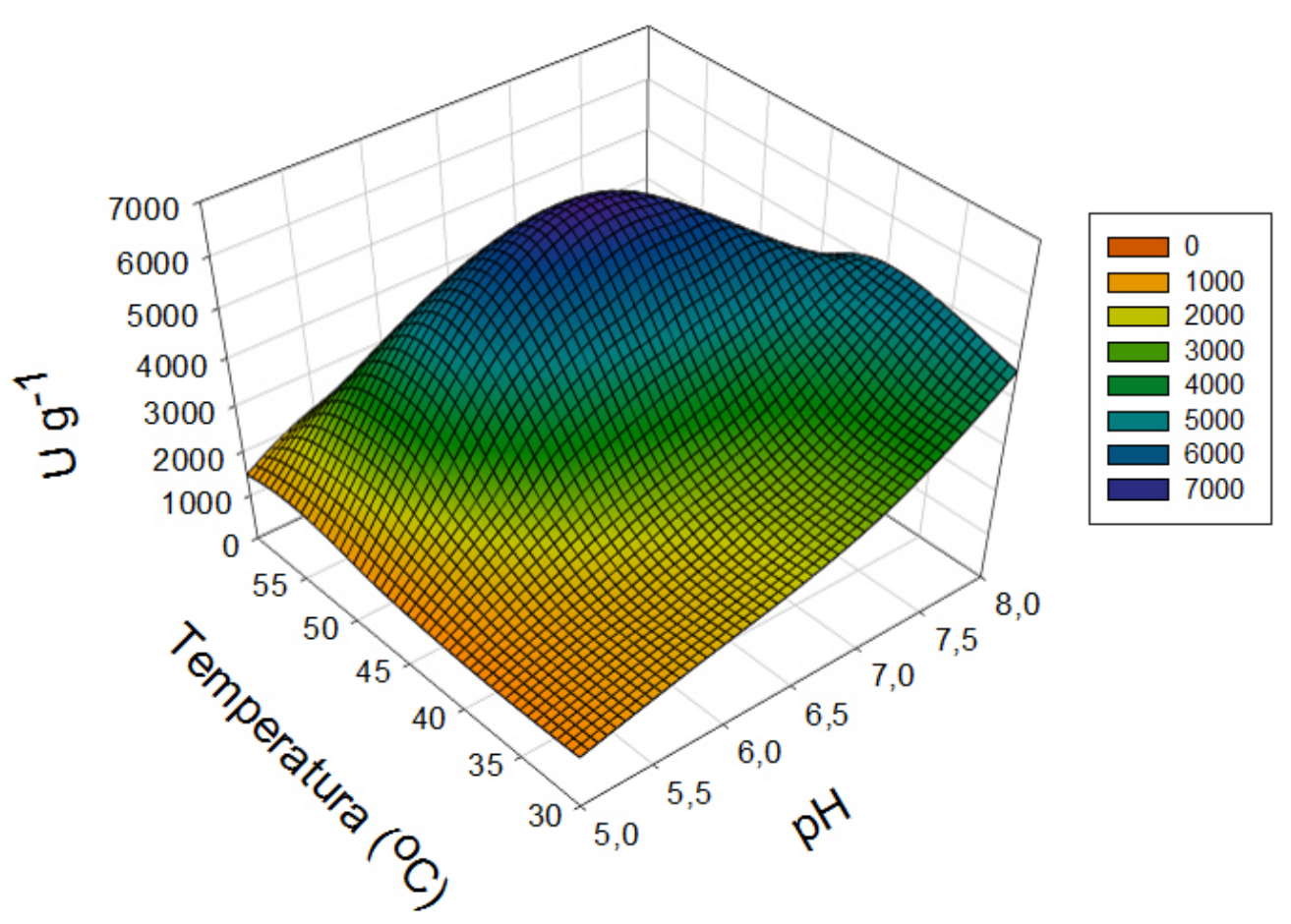

Figura 2. Efeito combinado entre o $\mathrm{pH}$ e a temperatura de reação sobre a atividade de peroxidase de Echinolaena inflexa $\left(\mathrm{U} \mathrm{g}^{-1}\right)$. 
A região que demonstrou condições ótimas de reação correspondeu aos ensaios realizados nas faixas de temperatura entre 45 a $55^{\circ} \mathrm{C}$ e de $\mathrm{pH}$ entre 7 e 8, faixa de $\mathrm{pH}$ semelhante ao utilizado no processo de extração para a espécie. Sob estas condições, a peroxidase de $E$. inflexa apresentou $6.250 \mathrm{U} \mathrm{g}^{-1}$ de farinha dos frutos.

Estes resultados são similares aos obtidos para as peroxidases de abacaxi e carambola, espécies também adaptadas a clima tropical, que apresentaram temperatura ótima para atividade na faixa de 50 a $55^{\circ} \mathrm{C}$ (Brito et al., 2005).

É possível ainda observar que, mesmo que a temperatura ótima tenha sido encontrada entre 45 a $55^{\circ} \mathrm{C}$, em todo o intervalo testado (entre 30 e $60^{\circ} \mathrm{C}$ ) há também atividade de peroxidase (Figura 2). Este comportamento pode ser atribuído à adaptação das gramíneas ao Cerrado. As plantas do bioma estão adaptadas a condições extremas, tais como alta insolação, solos rasos, secos e nutricionalmente pobres, além das temperaturas que variam grandemente ao longo do ano (Munhoz e Felfili, 2007).

Depois de estabelecidos esses parâmetros, o extrato da gramínea foi testado em função do tempo de reação, a $55^{\circ} \mathrm{C}$ (Figura 3). A influência do tempo de contato entre enzima e substrato foi significativa para os primeiros 10 min de reação, em que é possível observar aumentos bruscos na resposta enzimática. Após 15 min de tempo de reação o aumento na atividade passa a desacelerar, tendendo a estabilização.

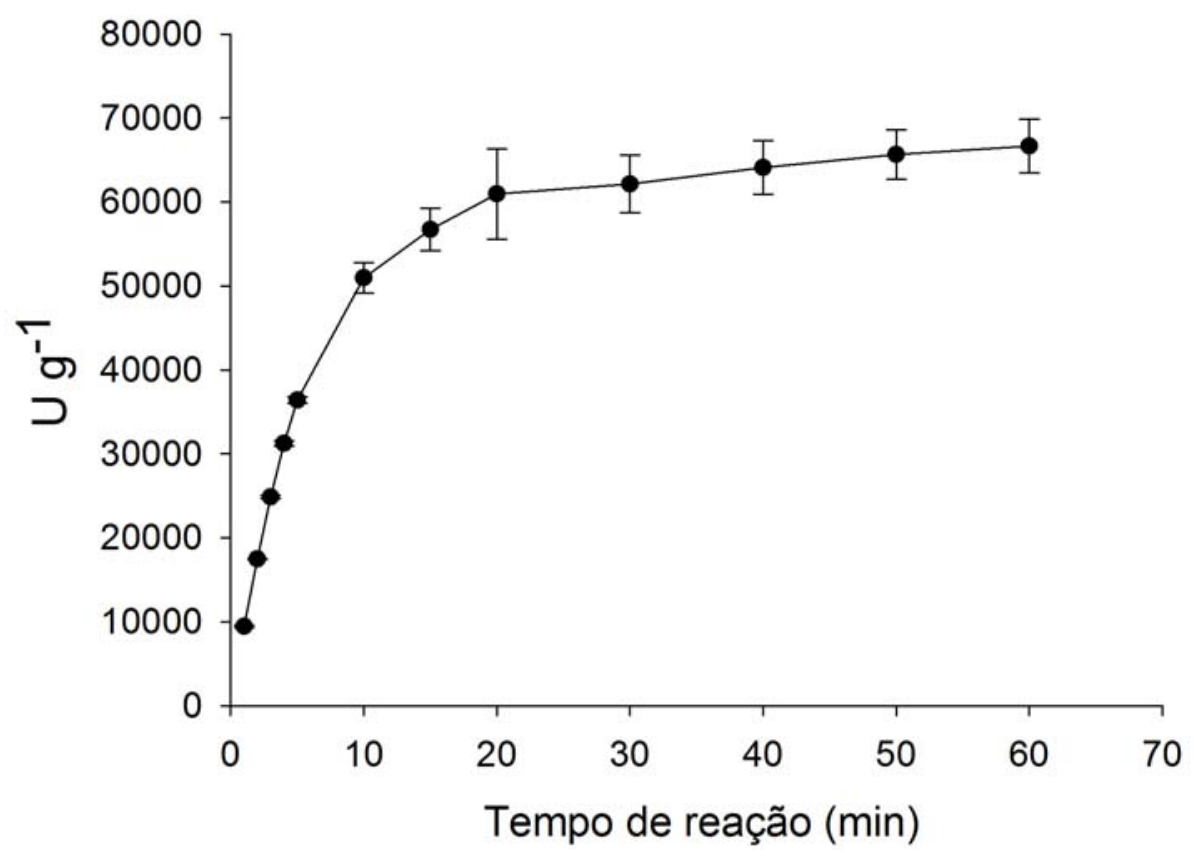

Figura 3. Efeito do tempo de incubação com os substratos pirogalol e peróxido de hidrogênio sobre a atividade de peroxidase em extrato aquoso de frutos de Echinolaena inflexa.

As peroxidases são uma das enzimas de maior estabilidade térmica presentes em frutas e vegetais (Berbicz e Clemente, 2001; Maciel et al., 2006). Este fato tem motivado grande interesse dos pesquisadores quanto aos estudos de inativação, tornando-a principal referência para se determinar quando o processamento térmico de frutas e vegetais foi ou não suficiente para manutenção de sua qualidade como alimentos (Neves e Silva, 2007).

A atividade de peroxidase diminuiu com o tempo de incubação na temperatura testada, no entanto manteve uma atividade de aproximadamente $11 \%$ após 5 min de tratamento. Com o aumento do tempo as atividades continuaram diminuindo, porém de forma mais lenta. Este resultado indica que a enzima é tolerante a temperaturas abaixo da ebulição. 
Berbicz e Clemente (2001) obtiveram resultados semelhantes a Echinolaena inflexa nos experimentos feitos com frutos de laranja. No tratamento térmico das enzimas de laranja a $80^{\circ} \mathrm{C}$, com 6 min a enzima manteve uma atividade entre 18 a 30\% em relação ao inicio do tratamento.

No tratamento térmico de peroxidases de carambola, goiaba e abacaxi aconteceu o mesmo padrão. A atividade da peroxidase diminuiu com o tempo, observando-se uma perda de aproximadamente $80 \%$ da atividade da enzima após tratamento térmico a uma temperatura de 75 a $85^{\circ} \mathrm{C}$ (Brito et al., 2005).

Nos testes com inibidores foi observada a boa capacidade de inibição da peroxidase pela ação do ácido ascórbico e menor inibição pelo ácido cítrico (Figura 4).

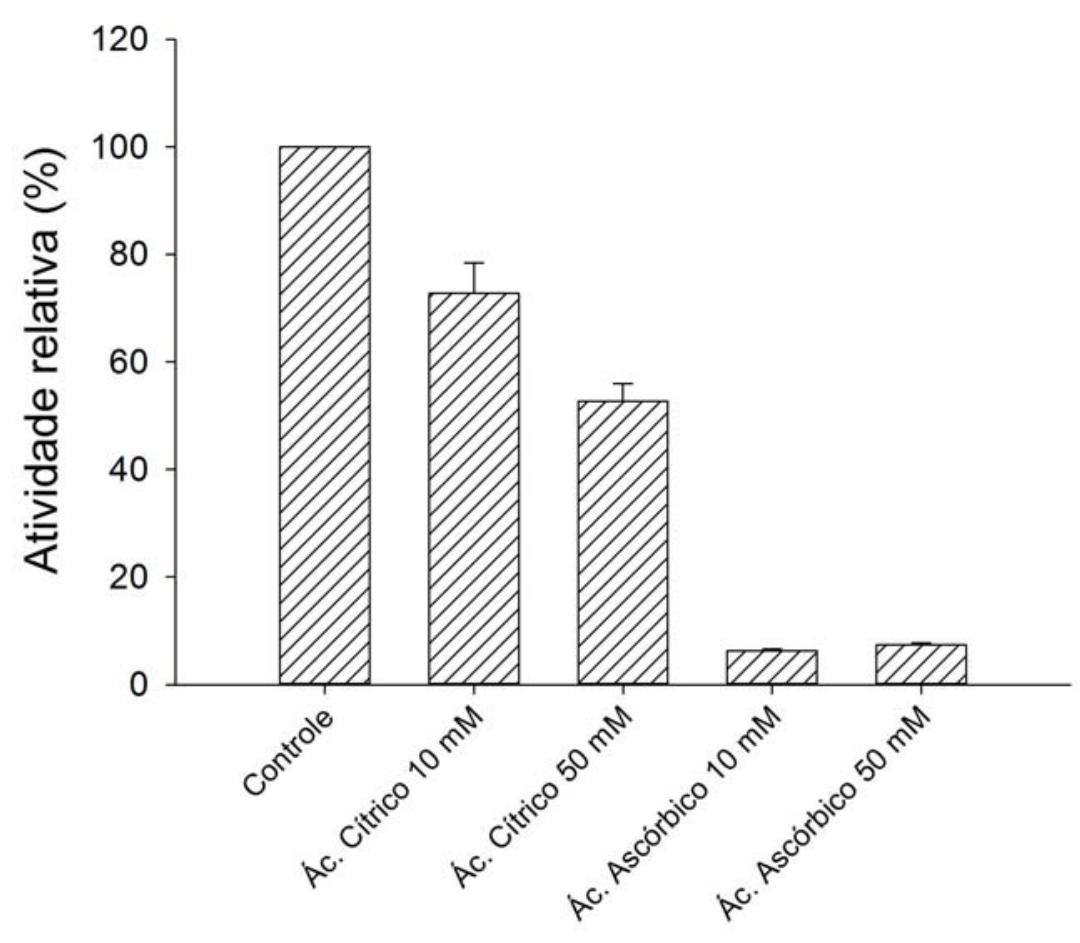

Figura 4. Efeito inibidor causado pelos ácidos na atividade de peroxidases de Echinolaena inflexa após 30 min.

O ácido ascórbico tem sido usado há mais de 50 anos como inibidor de escurecimento enzimático em alimentos de origem vegetal, muitas vezes combinado com ácidos orgânicos, tais como o ácido cítrico (Neves e Silva, 2007). O escurecimento resulta da degradação da antocianina pela ação de enzimas oxidativas, como polifenoloxidase (PPO), peroxidase (POD) e ascorbato oxidase. Os testes realizados corroboram o fato da enzima aqui estudada ser uma peroxidase clássica.

Neves e Silva (2007) também testaram o efeito do ácido ascórbico e do ácido cítrico no escurecimento enzimático. Os testes foram feitos com peroxidases de Yaco, e para elas o ácido ascórbico a $5 \mathrm{mmol} \mathrm{L}{ }^{-1}$ apresentou os melhores resultados nos seus experimentos, com uma redução de $27 \%$ de atividade em relação à amostra controle. O ácido cítrico se mostrou eficiente apenas em concentrações acima de $10 \mathrm{mmol} \mathrm{L}^{-1}$.

No caso deste trabalho o teste para avaliação de inibição de atividade nos extratos foi realizado para se confirmar se a atividade em questão era devido a ação de peroxidases. Assim como os testes com Yaco, os experimentos com Echinolaena inflexa tiveram grande inibição com ácido ascórbico mesmo em baixas concentrações. O papel do ácido ascórbico 
como inibidor se dá principalmente pela redução das quinonas em difenóis, evitando a formação de melaninas e na sua atuação inibidora enzimática como acidulante (Neves e Silva, 2007). O ácido cítrico também é amplamente empregado como acidulante e composto quelante.

A peroxidase de Echinolaena inflexa foi capaz de reagir com todos os compostos fenólicos testados e com amostras de efluente (Tabela 1). Entretanto, a maior capacidade de degradação de compostos fenólicos foi observada para o catecol, que foi de $87,5 \% \%$. Os resultados ainda demonstraram uma grande eficiência da enzima na degradação dos outros fenóis, sendo que foi capaz de degradar 67,83\% do pirogalol e 39,1\% do resorcinol.

Nos testes com efluentes agroindustriais (Tabela 1), a amostra de efluente bruto foi aquela em que a peroxidase de E. inflexa apresentou a maior capacidade de degradação de compostos fenólicos (29,1\%). Este resultado é interessante e promissor se levarmos em conta que uma amostra real de efluente dista em muito das condições laboratoriais otimizadas para os ensaios enzimáticos, em que há controle da concentração das espécies reagentes, da presença de contaminantes, do pH e da temperatura do meio, entre outros (Abd-Allah, 1999).

Tabela 1. Degradação de compostos fenólicos em amostras dos quatro pontos testados nos efluentes agroindustriais.

\begin{tabular}{lcc}
\hline \multicolumn{1}{c}{ Amostras } & $\begin{array}{c}\text { Capacidade de } \\
\text { degradação após 90 } \\
\text { min (\% média) }\end{array}$ & Desvio padrão \\
\hline $\begin{array}{l}\text { Córrego Abraão a montante do } \\
\text { lançamento do efluente }\end{array}$ & 7,3 & 12,7 \\
$\begin{array}{l}\text { Efluente bruto na entrada da ETE } \\
\text { Efluente tratado na saída da ETE }\end{array}$ & 29,1 & 5,2 \\
$\begin{array}{l}\text { Córrego Abraão a jusante do } \\
\text { lançamento do efluente }\end{array}$ & 11,0 & 0,5 \\
\hline
\end{tabular}

Klibanov (1983) realizou um dos primeiros trabalhos testando peroxidase em águas contaminadas. O autor usou HRP purificada e os experimentos mostraram o bom potencial, em alguns casos superior a 97\%, de descontaminação de fenóis, anilinas e outros compostos aromáticos de soluções aquosas.

Outros estudos recentes realizados com peroxidase livre e imobilizada tem-se mostrado igualmente eficientes no tratamento de fenóis e clorofenóis. Estudos mecanísticos com cloroperoxidases, peroxidase de rabanete, lignina peroxidase, manganês-peroxidase e lacase também têm sido realizados (Kamida et al., 2005).

A peroxidase de Rábano (HRP) é uma das mais estudadas, esta enzima catalisa a oxidação de vários substratos onde se incluem compostos aromáticos do tipo fenol, bifenol, anilinas, benzidinas e compostos heteroaromáticos relacionados. A HRP pode remover fenóis e aminas aromáticas diferentes da água, com eficiências de remoção para alguns poluentes superiores a 99\% (Akhtar e Husain, 2006). Outras fontes de peroxidase, como o melão-de-São-Caetano também já apresentaram boa capacidade para degradação de compostos fenólicos que ocorrem em efluentes de indústrias têxteis (Akhtar e Husain, 2006). O tratamento foi notavelmente eficaz em misturas de fenóis, mas a peroxidase solúvel deixou de funcionar depois de $3 \mathrm{~h}$, enquanto a peroxidase imobilizada continuou ativa. 


\section{CONCLUSÃO}

Este trabalho representa um primeiro esforço de se explorar novas alternativas ao tratamento de águas residuais. A capacidade de degradação de compostos fenólicos pela peroxidase de Echinolaena inflexa é comparável àquela estudada para outras fontes vegetais, mas com o diferencial de que a enzima continua ativa numa amostra real de efluente não-tratado.

O presente trabalho permitiu concluir que a gramínea Echinolaena inflexa apresentou um teor elevado de atividade da peroxidase, o que a torna fonte alternativa para aplicação em tecnologia enzimática. Os extratos de E. inflexa contendo peroxidase também foram capazes de degradar compostos fenólicos em condições controladas de laboratório e em amostras reais de efluente agroindustrial.

Entretanto, são importantes outros estudos para gerar reatores que possam tratar efluentes com compostos fenólicos de maneira alternativa e eficaz. Além disso, há a necessidade da realização de testes de caracterização de fenóis de cada efluente, para dessa forma entender a ação da enzima em águas de diferentes origens. A exploração de plantas do Cerrado, se feita de forma sustentável, pode resultar na descoberta e no desenvolvimento de ferramentas tecnológicas de baixo custo e de alta eficiência para a recuperação de águas contaminadas.

\section{AGRADECIMENTOS}

Ao Programa de Bolsas de Incentivo à Pesquisa PROBIP/UEG.

\section{REFERÊNCIAS}

ABD-ALLAH, A. M. A. Peroxidase Catalyzed Decontamination of Water Polluted with 2,4Dichlorophenols in Presence of Algae and Plant Materials. Journal of Abdulaziz University: Marine Sciences, v. 10, p. 41-45, 1999.

AKHTAR, S.; HUSAIN, Q. Potential applications of immobilized bitter gourd (Momordica charantia) peroxidase in the removal of phenols from polluted water. Chemosphere, v. 65, n. 7, p. 1228-1235, 2006. http://dx.doi.org/10.1016/j.chemosphere.2006.04.049

BERBICZ, F.; CLEMENTE, E. Avaliação da termoestabilidade e da regeneração da atividade da peroxidase extraída de laranja (Citrus spp.). Acta Scientiarum, v. 23, n. 5, p. 12391242, 2001.

BRADFORD, M. A rapid and sensitive method for the quantification of microgram quantities of protein-dye binding. Analytical Biochemistry, v. 72, p. 248-254, 1976. http://dx.doi.org/10.1016/0003-2697(76)90527-3

BRITO, C. A. K.; SATO, H. H.; SPIRONELLO, A.; SIQUEIRA, W. J. Características da atividade da peroxidase de abacaxis (Ananas comosus (L.) Merrill) da cultivar IAC Gomo-de-mel e do clone IAC-1. Ciência e Tecnologia de Alimentos, v. 25, n. 2, p. 244-249, 2005.

CHANCE, B.; MAEHLY, A. C. Assay of catalases and peroxidases. In: COLOWICK, S.P., KAPLAN, N. O. Methods in Enzymology. New York: Academic Press, 1955. V. 2, p. 764-775. 
HALPIN, B.; PRESSEY, R.; JEN, J.; MONDY, N. Purification and Characterization of Peroxidase Isoenzymes from Green Peas (Pisum sativum). Journal of Food Science, v. 54, n. 3, p. 644-649, 1989. http://dx.doi.org/10.1111/j.1365-2621.1989.tb04672.x

HAMID, M.; KHALIL-URREHMAN. Potential applications of peroxidases. Food Chemistry, v.115, n.4, p. 1177-1186, 2009. http://dx.doi.org/10.1016/j.foodchem.2009.02.035

KAMIDA, H. M.; DURRANT, L. R.; MONTEIRO, R. T. R.; ARMAS, E. D. Biodegradação de efluente têxtil por Pleurotus sajor-caju. Química Nova, v. 28, n. 4, p. 629-632, 2005. http://dx.doi.org/10.1590/S0100-40422005000400014

KLIBANOV, A. M. Peroxidase-Catalyzed Removal of Phenols from Coal-Conversion Waste Waters. Science, v. 221, n. 4607, p. 259-261, 1983.

LOWRY, O. H.; ROSBROUGH, N. J.; FARR, A. L.; RANDALL, R. J. Journal of Biological Chemistry, v. 193, p. 265-275, 1951.

MACIEL, H. P. F.; GOUVEA, C. M. C. P.; PASTORE, G. M. Obtenção de nova fonte de peroxidase de folha de Copaifera langsdorffii Desf. com alta atividade. Ciência e Tecnologia de Alimentos, v. 26, n. 4, p. 735-739, 2006.

MANNARINO, C. F.; MOREIRA, J. C.; FERREIRA, J. A.; ARIAS, A. R. L. Avaliação de impactos do efluente do tratamento combinado de lixiviado de aterro de resíduos sólidos urbanos e esgoto doméstico sobre a biota aquática. Ciência e saúde coletiva, v. 18, n. 11, p. 3235-3243, 2013. http://dx.doi.org/10.1590/S1413-81232013001100014

MUNHOZ, C. B. R.; FELFILI, J. M. Florística do estrato herbáceo-subarbustivo de um campo limpo úmido em Brasília, Brasil. Biota Neotropica, v. 7, n. 3, p. 205-215, 2007. http://dx.doi.org/10.1590/S1676-06032007000300022

NEVES, V. A.; SILVA, M. A. Polyphenol Oxidase from Yacon Roots (Smallanthus sonchifolius). Journal of Agricultural and Food Chemistry, v. 55, p. 2424-2430, 2007. http://dx.doi.org/10.1021/jf063148w

RATTER, J. A.; RIBEIRO, J. F.; BRIDGEWATER, S. The Brazilian Cerrado Vegetation and Threats to its Biodiversity. Annals of Botany, v. 80, p. 223-230, 1997. http://dx.doi.org/10.1006/anbo.1997.0469 